\title{
Comportamento térmico de lignina residual de pré-tratamento de biomassa lignocelulósica
}

O artigo apresenta o estudo comparativo entre três diferentes tipos de lignina recuperadas de licores negros de pré-tratamento de biomassas para a produção de etanol de segunda geração, sendo elas ligninas de arroz, arundo e de mistura de biomassa. Como enfoque principal aborda a caracterização térmica de ambas as ligninas, comparando-as entre si. As ligninas foram recuperadas através de precipitação com $\mathrm{H} 2 \mathrm{SO} 450 \%$ v/v e após processo de lavagem, procederam-se análises espectrofotométricas no infravermelho (FTIR), análise termogravimétrica (TGA) e calorimetria exploratória diferencial (DSC). Através da análise FTIR foram identificados os grupos funcionais $\mathrm{OH}, \mathrm{C}-\mathrm{C}, \mathrm{C}=\mathrm{O}$ e $\mathrm{C}=\mathrm{C}$ que são característicos de ligninas. Entretanto as análises por TGA indicaram que as três ligninas apresentaram teores semelhantes para umidade, e diferenças significativas com relação aos teores de voláteis e cinzas, confirmando a complexidade estrutural da lignina. Associada à análise termogravimétrica as ligninas foram submetidas à análise DSC para determinação da perda de energia, onde apesar de apresentar dois eventos endotérmicos a lignina de arundo apresentou uma menor absorção de energia em relação às ligninas de arroz e de mistura de biomassas.

Palavras-chave: Licor negro; Aproveitamento de resíduo; Etanol de $2 \mathrm{G}$; Biorrefinaria.

\section{Thermal behavior of residual lignin from lignocellulosic biomass pretreatment}

\begin{abstract}
The article presents a comparative study between three different types of lignin recovered from black liquor pre-treatment of biomass for the production of second generation ethanol, being them lignins of rice, arundo and biomass mixture. As the main approach, the thermal characterization of both lignins is compared to each other. The lignins were recovered through precipitation with $\mathrm{H} 2 \mathrm{SO} 450 \% \mathrm{v} / \mathrm{v}$ and after washing process, infrared spectrophotometric analysis (FTIR), thermogravimetric analysis (TGA) and differential exploratory calorimetry (DSC) were performed. Through FTIR analysis the functional groups $\mathrm{OH}, \mathrm{C}-\mathrm{C}, \mathrm{C}=\mathrm{O}$ and $\mathrm{C}=\mathrm{C}$ that are characteristic of lignins were identified. However, the TGA analysis indicated that the three lignins presented similar moisture content, and significant differences with respect to volatile and ash contents, confirming the structural complexity of the lignin. Associated with thermogravimetric analysis the lignins were submitted to DSC analysis to determine energy loss, where despite presenting two endothermic events the arundo lignin presented a lower energy absorption in relation to the rice lignins and biomass mixture.
\end{abstract}

Keywords: Black Liquor; Waste Recover; Second Generation Ethanol; Biorefineries.

Topic: Engenharia Ambiental

Reviewed anonymously in the process of blind peer.
Received: 06/04/2021

Approved: 27/04/2021
Luane Pauline Maciel Hoffmann

Universidade Federal de Pelotas, Brasil

http://lattes.cnpq.br/8089799451648727

luane hoffmann@hotmail.com

Juliana Silva Lemões (iD

Universidade Federal do Rio Grande do Sul, Brasil

http://lattes.cnpq.br/6208388995026123

http://orcid.org/0000-0002-7594-1636

julianalemoes@gmail.com

Adriana Gonçalves da Silva Manetti

Universidade Federal de Pelotas, Brasil

http://lattes.cnpq.br/0103882542744811

http://orcid.org/0000-0002-3137-4078

didialimentos@yahoo.com.br

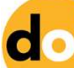

DOI: 10.6008/CBPC2179-6858.2021.004.0028
Patricia Oliveira Schmitt (D)

Universidade Federal de Pelotas, Brasil

http://lattes.cnpq.br/0436148916831903

http://orcid.org/0000-0003-1372-2881

patty olimitt@hotmail.com.br

Cláudia Fernanda Lemons e Silva (ic

Universidade Federal de Pelotas, Brasil

http://lattes.cnpq.br/8387065724345198

http://orcid.org/0000-0001-7187-7000

lemonsclau@gmail.com
Referencing this:

HOFFMANN, L. P. M.; LEMÕES, J. S.; MANETTI, A. G. S.; SCHMITT, P. O.; SILVA, C. F. L.. Comportamento térmico de lignina residual de prétratamento de biomassa lignocelulósica. Revista Ibero Americana de Ciências Ambientais, v.12, n.4, p.353-363, 2021. DOI: http://doi.org/10.6008/CBPC2179-6858.2021.004.0028 


\section{INTRODUÇÃO}

Atualmente diversas tem sido as preocupações e discussões mundiais, em relação ao aumento da demanda energética, que consequentemente acaba por acarretar outros problemas como, por exemplo, o esgotamento gradual dos combustíveis fósseis. Contudo esta questão levantada com relação ao setor energético, econômico e ambiental tem motivado a exploração de recursos renováveis para a produção sustentável de eletricidade, calor, combustíveis e produtos orgânicos (TOLMASQUIM et al., 2007).

No processo de produção de etanol de segunda geração, uma etapa fundamental é o pré-tratamento da biomassa lignocelulósica, onde a lignina é separada da celulose e hemicelulose. A separação se deve ao fato de que para a geração do etanol de segunda geração, somente a celulose e hemicelulose são aproveitadas, sendo assim necessária a remoção da lignina para que se obtenha um melhor rendimento durante o processo (SANTOS et al., 2012).

Durante a etapa de pré-tratamento do processo de produção de etanol de segunda geração, os materiais lignocelulósicos sofrem uma desorganização em seu complexo para que, posteriormente, a celulose seja convertida em glicose através de ações enzimáticas (KNAUF et al., 2004). Segundo Hatfiled et al. (2005), Karimi et al. (2006) e Pereira et al. (2013), ao final da etapa de pré-tratamento alcalino é obtido um licor negro rico em lignina residual.

A lignina é considerada o segundo polímero natural mais abundante no setor mundial, devido a sua representação de 10-25\% da biomassa lignocelulósica. De acordo com Kamm et al. (2006) a lignina está presente na parede celular e lamela média dos vegetais e pode ser definida como um complexo altamente amorfo e heterogêneo, constituído principalmente de unidades de fenil-propano, que se ligam a hemicelulose e celulose. A estrutura da lignina é difícil de ser definida devido a sua complexa formação e as suas modificações estruturais (PYE, 2008).

Em função de sua alta capacidade calorifica, a principal utilização da lignina tem sido a queima em caldeiras na maioria dos processos industriais de grande escala, visando gerar energia. Entretanto através de estudos mais aprofundados é possível se obter uma melhor utilização dos recursos, através do processo de conversão de biomassa em biocombustíveis, insumos químicos, materiais, alimentos e energia (CHIES et al., 2015).

O aproveitamento da lignina residual do processo de produção de E2G está inserido no contexto de biorrefinarias, que são todas as indústrias que adotam o processamento sustentável de biomassa para que ela possa ser transformada e utilizada para a produção de combustíveis, energia ou produtos químicos (FOUST et al., 2008).

As biorrefinarias podem apresentar muitas vantagens, e entre elas podemos citar a agregação de um maior valor as biomassas através da exploração do seu potencial máximo, que consequentemente irá acarretar no aumento da sua rentabilidade, redução da demanda energética e redução da emissão de gases do efeito estufa (FOUST et al., 2008). Outro aspecto importante é que a ampla diversidade de matérias primas utilizada acaba por reduzir a dependência da produção de somente um produto, aumentando assim a 
sustentabilidade da biomassa (GHATAK, 2011; IEA, 2010).

Neste trabalho explora-se a caracterização de ligninas residuais proveniente da etapa de prétratamento alcalino para obtenção de etanol de segunda-geração a partir de arundo e da palha de arroz.

\section{METODOLOGIA}

Foram avaliadas três ligninas recuperadas de resíduos de diferentes processos de pré-tratamento de biomassa para a produção de etanol de segunda geração. As ligninas utilizadas para a realização das análises deste trabalho foram obtidas através da precipitação dos licores negros gerados durante o processo de prétratamento da biomassa da planta inteira de Arundo donax L. e da palha de arroz da cultivar Puitá INTA CL. O licor negro é obtido nestes processos em uma quantidade de aproximadamente $10 \mathrm{~L}$ durante a etapa de pré-tratamento de $1 \mathrm{~kg}$ de biomassa. Conforme condições de pré-tratamento descritas abaixo: Lignina de biomassa de arundo: Hidróxido de sódio 1,0 M, 127ํㅡ, 30 minutos; Lignina de biomassa de arroz: Hidróxido de sódio 0,5 M, 127으, 30 minutos; Lignina de mistura das biomassas: É um licor resultante da mistura do licor obtido da biomassa de arundo e do obtido através da biomassa de arroz que foram armazenados juntos, constituindo um resíduo de laboratório, sendo assim apresenta diferentes concentrações de hidróxido de sódio, temperaturas e tempos de pré-tratamento.

No fluxograma abaixo (Figura 1) é representado as etapas desde a obtenção da lignina até a realização das análises.

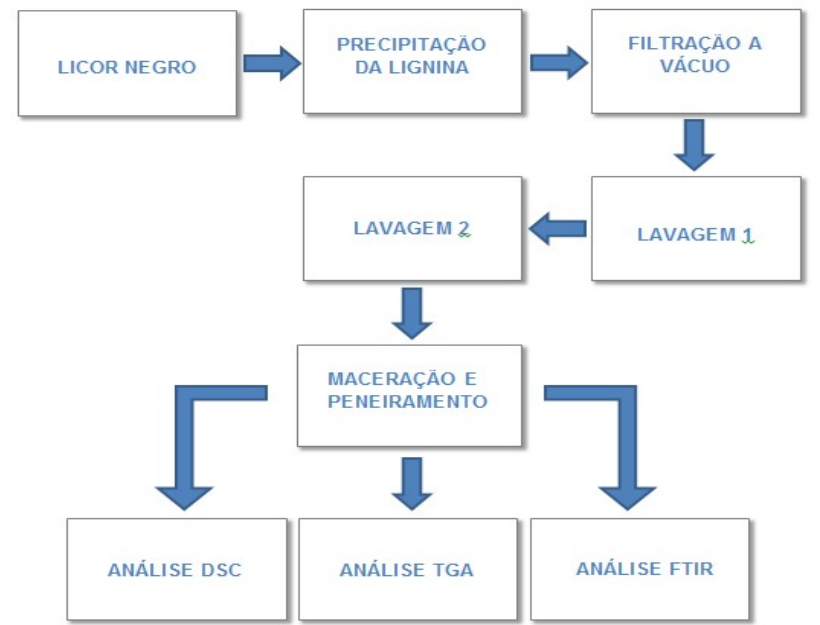

Figura 1: Fluxograma das etapas desenvolvidas para realizar o presente trabalho.

Ao licor negro, foi acrescentado ácido sulfúrico $\left(\mathrm{H}_{2} \mathrm{SO}_{4}\right) 50 \% \mathrm{v} / \mathrm{v}$ até se obter $\mathrm{pH} 2$ (BES et al., 2019). Após o processo de precipitação, a lignina passou pelo processo de separação através do método de filtração a vácuo. A lignina obtida foi seca em estufa a 40 ㄷ C até se obter uma massa constante (AVANCINI, 2019).

A lignina precipitada foi macerada e pesada. A lavagem foi realizada na proporção $1,5 \mathrm{~g}$ para $80 \mathrm{~mL}$ de água deionizada. Esta solução com o auxílio de um agitador magnético permaneceu em agitação por um período de 15 horas e então passou pela filtração a vácuo novamente, e secagem a 40 ํㅡ até ser obtida uma massa constante. O processo foi realizado mais uma vez e após estas duas etapas de lavagem, a lignina foi macerada e peneirada em peneira de $0,25 \mathrm{~mm}$ (AVANCINI, 2019). 
As análises de Espectroscopia no Infravermelho por Transformada de Fourier (FTIR) foram realizadas a partir de $2 \mathrm{mg}$ de cada amostra de lignina sendo realizadas em duplicatas. Os espectros no infravermelho foram obtidos através da utilização do equipamento IR Prestige 21 da marca Shimadzu, onde a faixa utilizada para a análise foi de $400-4000 \mathrm{~cm}^{-1}$, utilizando 60 scans com uma resolução de $4.0 \mathrm{~cm}^{-1}$.

As propriedades térmicas das ligninas foram determinadas através da análise termogravimétrica (TGA), em um termoanalisador DTG-60 Shimadzu. Foram utilizados para a análise aproximadamente $10 \mathrm{mg}$ de cada lignina, que foram colocadas em um cadinho de óxido de alumínio $\left(\mathrm{Al}_{2} \mathrm{O}_{3}\right)$ e aquecidas de 30 a $800^{\circ} \mathrm{C}$ com uma taxa de aquecimento de $10^{\circ} \mathrm{C} / \mathrm{min}$.

As análises das curvas de calorimetria exploratória diferencial (DSC) foram realizadas através da célula DSC-60 da Shimadzu, sob as seguintes condições experimentais: atmosfera dinâmica de nitrogênio com vazão de $50 \mathrm{~mL} / \mathrm{min}$; razão de aquecimento de $5 \circ \mathrm{C} / \mathrm{min}$, de $30 \circ \mathrm{C}$ a $300 \circ \mathrm{C}$; panelinha hermética de alumínio.

\section{RESULTADOS E DISCUSSÃO}

Através do processo de precipitação da lignina gerada para cada litro de licor negro utilizado, foram obtidos em média 5,25 g de fração sólida de lignina de arroz, 9,97 g de lignina de arundo e 6,97 g para a lignina de mistura de biomassas, após as etapas de lavagem (Tabela 1).

Tabela 1: Rendimento de lignina precipitada e após lavagens.

\begin{tabular}{lll}
\hline & Lignina precipitada (g/L) & 2o lavagem (g/L) \\
\hline Lignina de arroz & $21,00^{*}$ & $5,25^{*}$ \\
Lignina de Arundo & 17,34 & 9,97 \\
Lignina de mistura de biomassas & $11,07 * *$ & 6,56 \\
\hline
\end{tabular}

* Resultados obtidos por Avancini (2019)

** Resultados obtidos por Bes (2019)

Os resultados apresentados na Tabela 1 indicam que apesar da lignina de arroz apresentar um maior rendimento mássico após etapa de precipitação, a lignina de arundo foi a que apresentou o melhor rendimento depois de ser submetida ao processo de lavagem, com um rendimento de 9,97 g/L. Cada biomassa é distinta e apresenta diferenças entre quantidade e composição em relação aos componentes estruturais. Sendo assim as variações encontradas neste trabalho em relação às ligninas de diferentes origens, podem ser explicadas devido a diferentes fatores, como por exemplo, as condições de prétratamento utilizadas, o que pode influenciar rendimento de obtenção de lignina a partir do licor negro. (SANTOS et al., 2013).

Segundo Sobrinho et al. (2015) após passar pelo processo de precipitação, a lignina pode apresentar compostos solúveis em água, sendo assim importante a lavagem para a remoção destes elementos indesejados. O processo de lavagem é uma etapa do processo de extrema importância, pois através dela é realizada a remoção dos sais formados durante a precipitação da lignina, deixando a assim mais pura.

A diferença de cor entre a lignina precipitada e a lignina após passar pelos dois processos de lavagens pode ser observada na Figura 2. A lignina antes de passar pelos dois processos de lavagem, apresenta uma coloração esbranquiçada, e após as lavagens apresenta uma coloração, que varia de marrom escuro ao preto. 


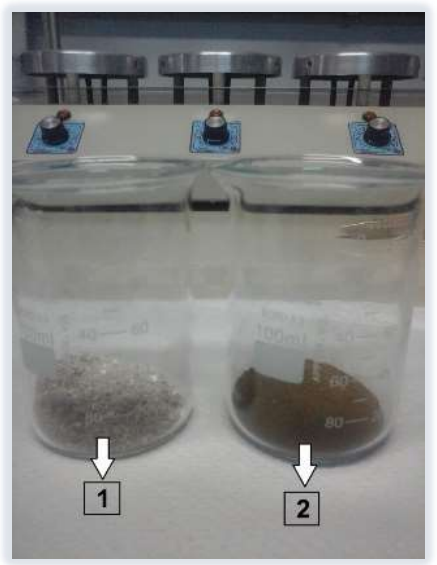

Figura 2: Diferença de cor da lignina de mistura de biomassas.

\section{Espectroscopia no infravermelho (FTIR)}

Segundo Azadfar (2015) uma das aplicações da espectrometria na região do infravermelho tem sido o estudo dos grupos funcionais nas macromoléculas da lignina.

Os espectros no infravermelho das três ligninas estão apresentados na Figura 3. Para ambas as biomassas, foi possível observar banda característica referente ao estiramento de hidroxilas (OH) nos grupamentos ligados a anéis aromáticos e cadeias alifáticas com uma absorção máxima em $3.500 \mathrm{~cm}^{-1}$. A banda localizada em $2.900 \mathrm{~cm}^{-1}$ corresponde ao estiramento de ligações simples entre carbono e hidrogênio de grupos alifáticos (C-H) foi observada em todas as ligninas analisadas. A absorção em $1.750 \mathrm{~cm}^{-1}$ é referente ao estiramento de dupla ligação entre carbono e oxigênio $(C=0)$. A absorção com máximo em $1.600 \mathrm{~cm}^{-1}$ corresponde ao estiramento de ligações duplas de carbono em anel aromático ( $C=C$ aromático) (LABAT, 2008; WATKINGS et al., 2015).

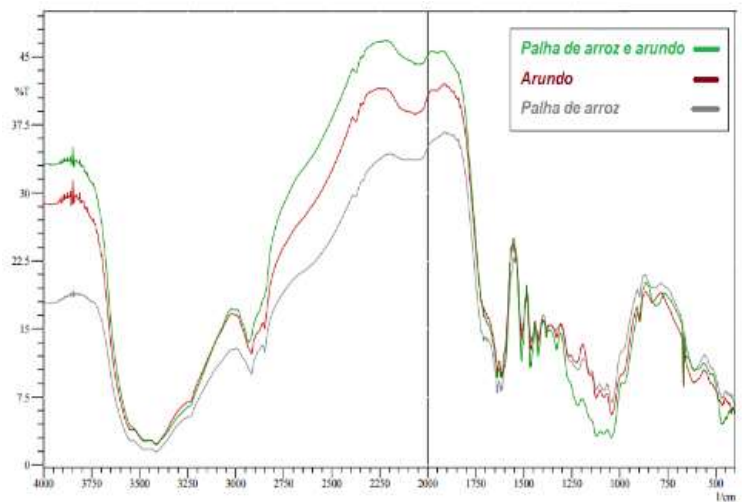

Figura 3: Espectro de infravermelho de lignina de palha de arroz (cinza), arundo (vermelho) e mistura palha de arroz e arundo (verde).

Os resultados expressos nos espectros no infravermelho confirmam que a lignina de arroz, lignina de arundo e a lignina de mistura de biomassa apresentaram composição e tipos de ligações químicas dos compostos muito semelhantes. Contudo as pequenas diferenças observadas com relação à intensidade podem ser explicadas pelas diferentes composições em função do tipo de planta, idade entre outras. Gambarato et al. (2015) apresentou em seu artigo, a caracterização da palha de cana-de-açúcar. O autor utilizou o processo de acidólise branda para a obtenção da lignina. Um dos métodos utilizados para a 
caracterização da lignina foi a Espectroscopia no Infravermelho (FTIR). Em sua análise encontrou a presença de estiramento $\mathrm{C}-\mathrm{H}$ na região de $2960-2842 \mathrm{~cm}^{-1}$, resultado muito semelhante ao apresentado neste trabalho, onde se encontrou o mesmo estiramento em $2.900 \mathrm{~cm}^{-1}$. $O$ estiramento referente ao grupamento de carbonilas e carboxilas não conjugadas e $C=0$, foi encontrado por Gambarato et al. (2015) em $1.705 \mathrm{~cm}^{-1}$, enquanto que no presente trabalho foi encontrado o mesmo grupo funcional em $1.750 \mathrm{~cm}^{-1}$. O autor também encontrou ligações referentes a carbonilas e carboxilas conjugadas além de $C=0$ em $1630 \mathrm{~cm}^{-1}$, e deformação C-H combinada com a vibração do anel aromático a $1463 \mathrm{~cm}^{-1}$.

\section{Análise termogravimétrica (TGA)}

A técnica de análise termogravimétrica é muito importante para a avaliação dos comportamentos térmicos na lignina, que ao decorrer do tempo passa por um processo de degradação térmica através de um longo intervalo de temperatura, esta degradação ocorre devido ao fato de seus diferentes grupos funcionais a base de oxigênio possuir uma estabilidade térmica diferente (LAURICHESSE et al., 2014). No entanto a TGA sozinha não é suficiente para interpretar a perda de massa da amostra (PARTHASARATHY et al., 2013).

Na Figura 4 está representada a curva termogravimétrica da lignina do resíduo de palha de arroz, onde é possível observar a presença de 3 picos, no primeiro temos uma perda de $6,20 \%$ da massa de $33,72 \circ \mathrm{C}$ a 76,86으, referente à perda de umidade presente na lignina obtida da palha de arroz. Nas temperaturas de 251,98ㄷ a 302,58 C obteve-se 21,9\% de perda mássica, que está relacionada à perda de voláteis. O último pico ocorre entre 309,06 ํ C e 402,11 ํ C sendo apresentada uma redução de $28,78 \%$ da massa devido a queima de compostos voláteis. Ao final do processo temos uma perda total de voláteis de $50,68 \%$. Como resultado da análise para a amostra de lignina de arroz se obteve uma perda total da massa de aproximadamente $56,88 \%$, sobrando assim cerca de $43,12 \%$ de cinza da amostra.

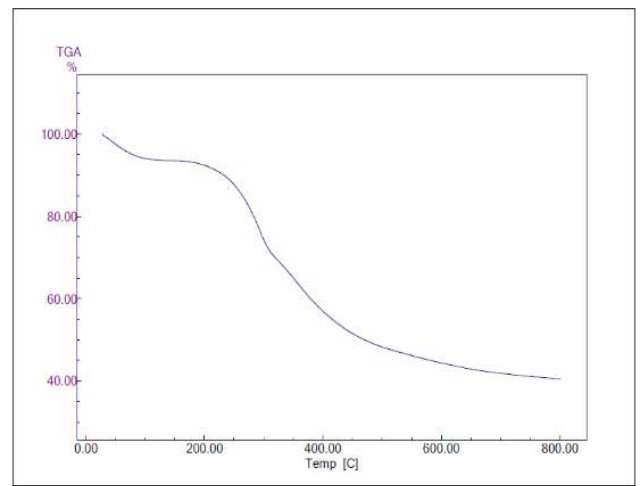

Figura 4: Curva termogravimétrica (TGA) de lignina de palha de arroz.

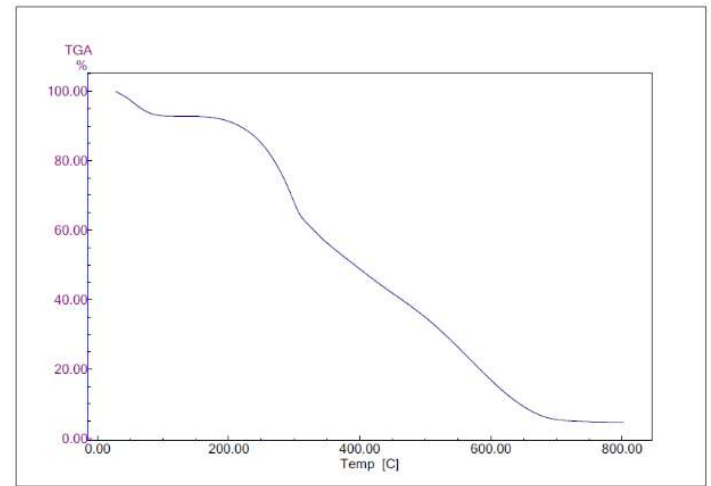

Figura 5: Curva termogravimétrica (TGA) de lignina de arundo.

Já na termogravimetria da lignina de arundo representada na Figura 5, constatou-se uma perda de $6,92 \%$ da massa entre $36,92^{\circ} \mathrm{C}$ e $74,72^{\circ} \mathrm{C}$. Assim como na análise da lignina de arroz, a perda de massa nesta faixa de temperatura é referente ao percentual de umidade presente na amostra de arundo. Entre as temperaturas de 247,76 ㄷ a 305,49 ㄷ C a perda de massa devido à queima de voláteis é de $28,67 \%$. E o último pico apresenta uma redução de $54,20 \%$. Obtendo uma porcentagem total de $82,87 \%$ de perda de materiais 
voláteis. Como resultado da análise da lignina de arundo chegou-se a uma perda total da massa de aproximadamente $89,79 \%$, sobrando assim cerca de $10,21 \%$ de cinza da amostra.

Na Figura 6 está representada a termogravimetria da lignina de mistura de biomassas (arroz e arundo). No intervalo das temperaturas de 38,20 으 e 78,92 으 C houve uma perda de $6,30 \%$ da massa relacionada ao teor de umidade presente na amostra. Na faixa de temperatura de 251,72 ㅇ $\mathrm{C}$ a 312,59 o $\mathrm{C}$ ocorreu uma perda de massa de $23,47 \%$. Por último observou-se uma redução mássica de $39,00 \%$ no intervalo de 498,24 ㄷ e 564,12 드, apresentando uma redução total de $62,47 \%$ da massa devido a queima de compostos voláteis. Como resultado da análise da lignina de mistura de biomassas se obteve uma perda total da massa de aproximadamente $68,77 \%$, sobrando assim $31,23 \%$ de cinza da amostra.

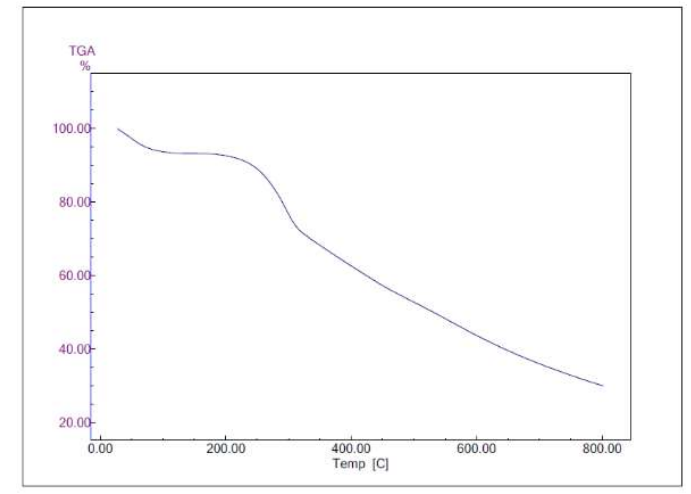

Figura 6: Curva termogravimétrica (TGA) de lignina de palha de arroz e planta inteira de arundo.

Considerando que na representação das curvas termogravimétricas, os degraus indicam as variações de massa que ocorreram na amostra durante a reação térmica. A TGA é uma técnica analítica que apresenta resultados quantitativos e qualitativos de uma forma rápida e reprodutível (DENARI et al., 2012)

Segundo Klautau (2008), fatores como os teores de umidade, de cinzas e de voláteis presentes em uma biomassa podem influenciar em sua combustão. Devido à redução da quantidade de energia que é convertida em calor, biomassas com percentuais acima de 50\% de umidade não são aconselháveis para utilização como combustível.

Os resultados obtidos para os teores de umidade em ambas as amostras estão dentro dos valores aceitáveis para a sua utilização como combustíveis encontrados na literatura. A lignina de arroz foi a que obteve o menor teor de materiais voláteis com uma taxa de 50,68\%. Biomassas com um alto teor de compostos inorgânicos tem o seu poder calorifico prejudicado e também são responsáveis por gerar cinzas ao final do processo de combustão (STREHLER, 2000).

Teores elevados de cinzas podem afetar o poder calorifico e gerar uma maior quantidade de resíduo. A lignina de arundo apresentou teores de cinzas semelhantes ao da literatura, já para a lignina de arroz os teores foram elevados, o que pode justificar o teor alto também encontrado para a lignina de mistura de biomassas. Portanto a lignina que apresentou o melhor resultado para cinza foi a lignina de arundo com $10 \%$ de teor de cinzas, indicando, segundo este parâmetro, ser mais vantajosa em relação as demais para uso em processos de geração de energia por combustão.

Gambarato et al. (2015) realizaram a análise térmica da lignina de cana-de-açúcar, utilizando uma 
taxa de aquecimento de $10^{\circ} \mathrm{C} \cdot \mathrm{min}^{-1}$, sob atmosfera de nitrogênio, na faixa de temperatura de $25-800^{\circ} \mathrm{C}$. Através do trabalho observaram uma primeira etapa de degradação em aproximadamente 154ำC, já a degradação da lignina ocorre em um intervalo de temperatura que vai de $154^{\circ} \mathrm{C}$ até a temperatura de $800^{\circ} \mathrm{C}$.

\section{Calorimetria exploratória diferencial (DSC)}

$\mathrm{Na}$ análise térmica por DSC de palha de arroz (Figura 7) é possível observar um evento endotérmico que pode ser explicado por processos de fusão, perda de massa da amostra, dessorção e reações de apoio. Este evento apresenta uma temperatura inicial de $144,45^{\circ} \mathrm{C}$, um pico endotérmico á $146,53^{\circ} \mathrm{C}$, até atingir uma temperatura final de $151,22^{\circ} \mathrm{C}$, sendo que a energia absorvida durante este evento foi de $581,61 \mathrm{~mJ}$. Ao se observar a curva obtida, é possível constatar devido ao fato de o pico apresentar forma estreita que a lignina de arroz não é heterogênea (MIRANDA et al., 2009).

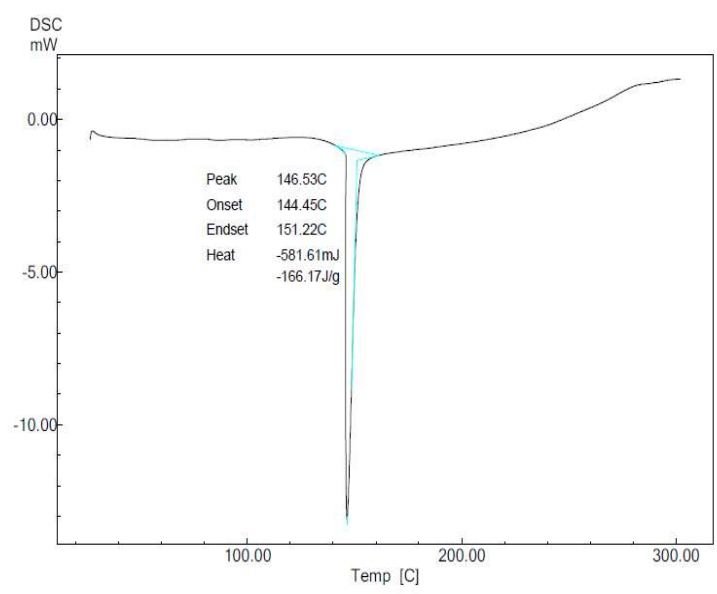

Figura 7: Termograma de calorimetria diferencial de varredura de lignina de palha de arroz.

O gráfico apresentado pela análise da biomassa de arundo (Figura 8) apresenta dois picos endotérmicos e um exotérmico. Os picos endotérmicos podem ser explicados por fusão, enquanto que o exotérmico ocorre devido à oxidação ou decomposição da lignina analisada. O primeiro evento endotérmico possui um início e fim em $136,02^{\circ} \mathrm{C}$ e $140,90^{\circ} \mathrm{C}$ respectivamente, onde temos um pico endotérmico a uma temperatura de 133,11으 e uma absorção energética de 17,50 mJ. Já o segundo evento endotérmico apresentado pela lignina de arundo tem um início e fim ao atingir as temperaturas de $143,38^{\circ} \mathrm{C}$ e $167,04^{\circ} \mathrm{C}$ respectivamente e um pico em $150,75^{\circ} \mathrm{C}$, este segundo evento apresentou uma absorção energética de 129,49 mJ. Através da curva obtida, é possível observar que a lignina de arundo apesar de ter mais eventos endotérmicos em sua análise, ela apresenta uma menor absorção de calor e é mais heterogênea que a lignina de arroz. Sendo assim a lignina de arundo nesta análise apresenta resultados inferiores aos obtido pela lignina de arroz para aplicação para geração de energia.

O resultado para a análise da lignina de mistura de biomassas (Figura 9) demonstra um evento endodérmico. O evento endotérmico inicia em $139,62^{\circ} \mathrm{C}$ e termina ao atingir $148,74^{\circ} \mathrm{C}$, tendo um pico endotérmico a uma temperatura de $140,70^{\circ} \mathrm{C}$, e uma absorção de calor de $377,07 \mathrm{~mJ}$. Ao se observar a curva obtida é possível constatar que a amostra não é heterogênea. 


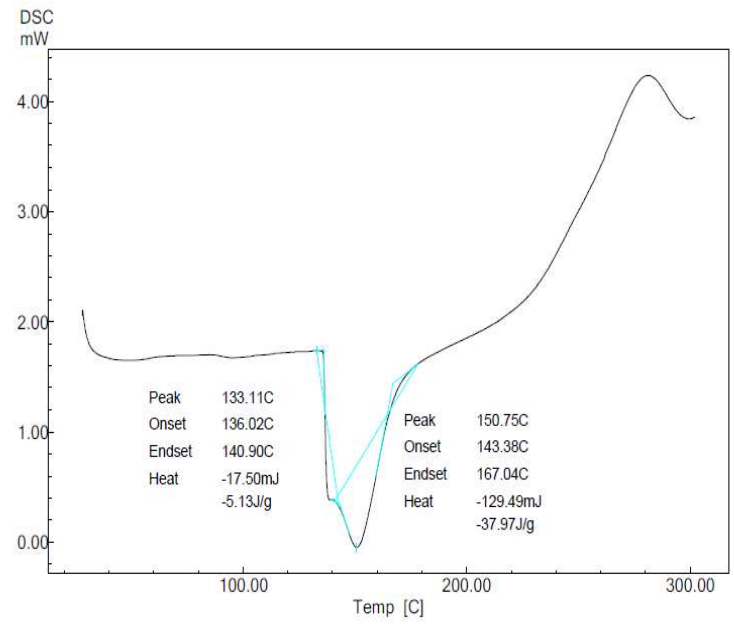

Figura 13: Termograma de calorimetria diferencial de varredura de lignina de arundo.

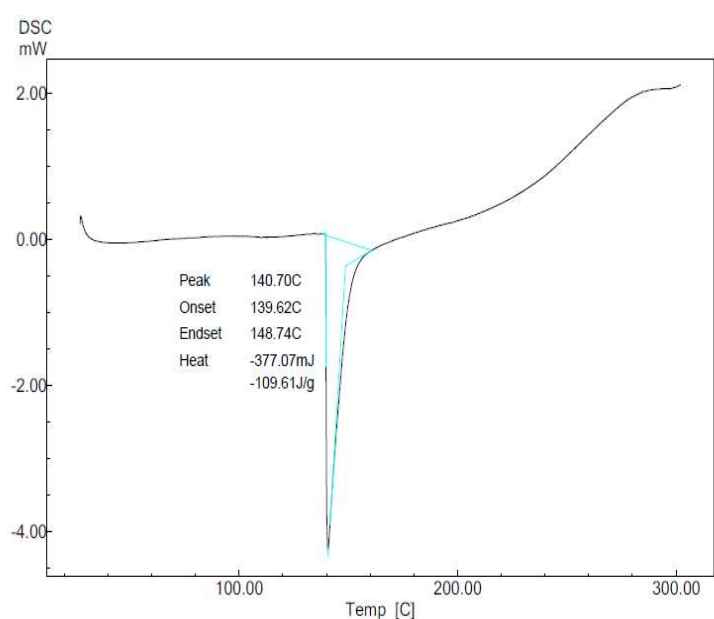

Figura 9: Termograma de calorimetria diferencial de varredura de lignina de mistura palha de arroz e arundo.

Através das análises DSC foi possível observar que as ligninas provenientes de arundo, arroz e a mistura de biomassa apresentam diferentes compostos e isto pode estar relacionado às diferentes condições de processos de pré-tratamento na produção de etanol de segunda geração.

Com relação a ensaios de calorimetria diferencial, Mello et al. (2008) utilizou para análise da amostra de Acácia Mearnsii De Wildo, parâmetros de temperatura ambiente até 500 드, à taxa de $50 \mathrm{~mL} / \mathrm{min}$, empregando-se uma taxa de aquecimento de $10^{\circ} \mathrm{C} \mathrm{min}^{-1}$. O autor encontrou picos de $379,6 \circ \mathrm{C}$ e $387^{\circ} \mathrm{C}$ para cadinho aberto e fechado respectivamente. Os resultados apresentados no presente trabalho onde foram observados picos endotérmicos de 146,53 으, $150,75 \mathrm{C}$ e 140,70 으 $\mathrm{C}$ para as amostras de arroz, de arundo e mistura de biomassas respectivamente, foram menores que os encontrados pelo autor. A diferença pode ser explicada pelo fato de as ligninas serem de espécies distintas.

Freitas et al. (2017), analisou amostras de casca de arroz, para a análise foi utilizado o equipamento DSC TA 2010 e o procedimento ocorreu entre 20 e $500^{\circ} \mathrm{C}$, com taxa de aquecimento de $10^{\circ} \mathrm{C} / \mathrm{min}$. A amostra de casca de arroz apresenta evento endotérmico em 74 ํㅡ, sendo este evento associado a liberação de água adsorvidas em suas estruturas. A lignina da casca de arroz também mostrou dois eventos exotérmicos em 290 ㄷ C e 402 ํ C, associados a volatilização de compostos orgânicos. Os resultados deste trabalho que apresenta pico endotérmico em 146,53으, foram diferentes dos encontrados por Freitas et al. (2017).

Miranda (2009) também analisou a palha de cana-de-açúcar, porém a autora realizou as análises até a temperatura de $800^{\circ} \mathrm{C}$. Foi possível observar nos resultados obtidos pelo autor um primeiro evento endotérmico em $52^{\circ} \mathrm{C}$ referente a perda de umidade da amostra, já o segundo evento endotérmico ocorre de $330^{\circ} \mathrm{C}$ a $600^{\circ} \mathrm{C}$ e mostra a degradação térmica da hemicelulose e celulose.

Cada biomassa é distinta e apresenta diferenças entre quantidade e composição em relação aos componentes estruturais. Sendo assim as variações encontradas neste trabalho em relação às ligninas de diferentes origens, podem ser explicadas devido a diferentes fatores, como por exemplo, a lignina precipitada de primeira lavagem e segunda lavagem, lignina de arroz, lignina de Arundo, lignina de mistura de biomassas, condições de pré-tratamento utilizadas, o que pode influenciar rendimento de obtenção de lignina a partir do licor negro (SANTOS et al., 2013). 


\section{CONCLUSÕES}

$\mathrm{Na}$ análise de espectroscopia no infravermelho por transformada de fourier (FTIR), pôde-se observar que todas as intensidades podem ser explicadas devido ao fato de as ligninas utilizadas neste trabalho serem distintas, como por exemplo, o arroz utilizado era só palha, já o arundo era a planta inteira.

Já na análise termogravimétrica (TGA) observaram-se resultados semelhantes para os teores de umidade e a existência de uma significativa diferença entre os teores de cinzas, e voláteis para todas as ligninas. $\mathrm{O}$ que indica que podem ser utilizadas como combustíveis. $O$ teor de umidade é um fator a ser considerado, pois interfere nas análises térmicas e neste estudo não se apresentou diferenças entre as ligninas oriundas de diferentes biomassas.

No caso das cinzas, a lignina de arundo apresentou percentual próximo ao da literatura, já a biomassa de arroz demonstrou um teor de cinza elevado o que pode ter causado um aumento na lignina de mistura de biomassas, essa diferença pode ser considerada como consequência da diferença na composição das biomassas e temperaturas empregadas para a execução dos ensaios.

Já os teores de voláteis, mesmo apresentando diferença entre as ligninas aqui estudadas, se apresentam como uma forte alternativa para a utilização energética. Através das análises DSC foi possível concluir que as três ligninas estudadas neste trabalho demonstraram resultados diferentes para absorção de energia e intervalos de temperatura para picos, início e fim dos eventos apresentados.

Ao se comparar as três ligninas, conclui-se assim que a lignina de arundo se apresenta como a melhor opção para aplicações futuras, considerando que a porcentagem de cinzas geradas pela amostra é menor em relação às outras, apesar de apresentar uma absorção de energia menor que a apresentada pela lignina de arroz e a lignina de mistura de biomassas.

\section{REFERÊNCIAS}

AVANCINI, A. R.; LEMOES, J. S.; MATOSO, E. S.; CRUZ, N. D. SILVA, S. D. A.; SILVA, C. F. L.; Residual lignin from biomass pretreatment for $2 \mathrm{~g}$ ethanol production as an adsorbent in dye removal. Ciência e Natura, Santa Maria, v.41, p.265-270, 2019.

AZADFAR, M.; GAO, A. H.; BULE, M. V.; CHEN, S.. Structural characterization of lignin: A potential source of antioxidants guaiacol and 4-vinylguaiaco. International Journal of Biological Macromolecules, Washington, v.75, p.58-66, 2015. DOI:

https://doi.org/10.1016/j.ijbiomac.2014.12.049

BERNAL, C.; COUTO, A. B.; BREVIGLIERI, S. T.; CAVALHEIRO, E. T. G.. Influência De Alguns Parâmetros Experimentais Nos Resultados De Análises Calorimétricas Diferenciais - DSC.

Quim. Nova, v.25, n.5, p.849-855, 2002. DOI: https://doi.org/10.1590/S0100-40422002000500023

BES, K.; LEMOES, J. S.; SLVA, C. F. L.; SILVA, D. A. S.. Extração e caracterização da lignina proveniente do pré-tratamento de biomassa para produção de etanol de $2^{\text {a }}$ geração.

Engenharia Sanitária e Ambiental, Rio de Janeiro, v.24, n.1, p.55-60, 2019.
CHIES, V.; PICHELLI, K.. Carvão vegetal: de problema a solução: Agroenergia em Revista, v.4, n.9, 2015.

DENARI, G. B., CAVALHEIRO, E. T. G.. Princípios e aplicações de análises térmicas. Material de apoio curso teórico prático - São Carlos: Universidade de São Carlos, 2012.

FOUST, T. D.; IBSEN, K. N.; DAYTON, D. C.; HESS, J. R.; KENNEY, K. E.. The Biorefinery. In: Biomass Recalcitrance: Deconstructing the Plant Cell Wall for Bioenergy. Oxford: Blackwell Publishing, 2008. p.7-37.

GAMBARATO, B. C.; VITORETTI, F. P.; GONÇALVES, A. R.. Caracterização Espectroscópica E Análise Térmica Da Lignina Da Palha De Cana-De-Açúcar. In: SIMPÓSIO DE HIDRÓLISE ENZIMÁTICA DE BIOMASSA, 20, Anais. Fortaleza: UFC, 2015. DOI: https://doi.org/10.17648/sinaferm-2015-32140

GHATAK, H. R.. Biorefineries from the perspective of sustainability: Feedstocks, products, and processes. Renewable and Sustainable Energy Reviews, v.15, p.40424052, 2011. DOI: https://doi.org/10.1016/j.rser.2011.07.034

HATFILED, R., FUKUSHIMA, R.S.. Can lignin be accurately measured? Crops Science, v.45, n.3, p.832-839, 2005. DOI: 


\section{https://doi.org/10.2135/cropsci2004.0238}

IEA. International Energy Agency. Technology Roadmaps: Biofuels for transport, p.56, France, 2011.

KAMM, B.; GRUBER, P. R.; KAMM, M.. Biorefineries: Industrial Processes and Products. Weinheim, 2006. DOI: https://doi.org/10.1002/9783527619849

KARIMI, K.; KHERADMANDINIA, S.; TAHERZADEH, M. J.. Conversion of rice straw to sugars by dilute-acid hydrolysis. Biomass \& Bioenergy, v.30, p.247-253, 2006. DOI: http://doi.org/10.1016/j.biombioe.2005.11.015

KLAUTAU, J. V. P.. Análise Experimental de uma Fornalha a Lenha de Fluxo Co-corrente para Secagem de Grãos. Dissertação (Mestrado em Engenharia Ambiental) Universidade Federal do Paraná, Curitiba, 2008.

KNAUF, M.; MONIRUZZAMAN, M.. Lignocellulosic biomass processing: a perspective. Tunbridge Wells, v.106, n.1263, p.147-150, 2004. DOI:

http://doi.org/10.4236/jpee.2014.24021

LABAT, G. A. A.. Estudo cinético da oxidação de ligninas obtidas da palha e do bagaço de cana e aplicações de lignina de bagaço em resinas à base de materiais naturais. Dissertação (Mestrado em Biotecnologia Industrial) Universidade de São Paulo, Lorena, 2008. DOI: http://doi.org/10.11606/D.97.2008.tde-27092012-122112

LAURICHESSE, S.; AVÉROUS, L.. Chemical modification of lignins: Towards Biobased Polymers. Progress in Polymer Science, v.39, n.7, p.1266-1290, 2014. DOI: http://doi.org/10.1016/j.progpolymsci.2013.11.004

MELLO, F. S.; STOLZ, A. S.; MORISSO, F. D. P.; MÜHLEN, C. V.; MOURA, A. B. D.; RIEGEL, I. C.. Estudo do comportamento térmico da acácia negra por calorimetria exploratória diferencial (DSC) e análise termogravimétrica (TGA). Revista Tecnologia e Tendências, v.7, n.2, p.11-20, 2008. DOI: https://doi.org/10.25112/rtt.v7i1\%20e\%202

MIRANDA, L. F. R.; SELMO, S. M. S.. Avaliação de argamassas com entulhos reciclados, por procedimentos racionais de dosagem. In: SIMPÓSIO BRASILEIRO DE TECNOLOGIA DAS ARGAMASSAS, 3. Anais. Vitória: PPGEC/ANTAC, 1999.

PARTHASARATHY, R. P.; BASAVARAJ, G.; BASU, K.; REDDY, C. R.; KUMAR, A. A.; REDDY, B. V. S.. Economics of sweet sorghum feedstock production for bioethanoll. In: REDDY, B. V. S.; KUMAR, A. A.; REDDY, C. R.; PARTHASARATHY, R. P.. Developing a sweet sorghum ethanol value chain. Hyderabad: ICRISAT, 2013. p.99-109.

PEREIRA, B. L. C.; CARNEIRO, A. C. O.; CARVALHO, A. M. M. L.; TRUGILHO, P. F.; MELO, I. C. N. A.; OLIVEIRA, A. C.. Estudo da degradação térmica da madeira de Eucalyptus através de termogravimetria e calorimetria. Revista Árvore, Viçosa, v.37, n.3, p.10, 2013. DOI: https://doi.org/10.1590/S0100$\underline{67622013000300020}$

PYE, E. K.. Industrial lignin production and applications. In: KAMM, B.; GRUBER, P. R.; KAMM, M.. Biorefineries: industrial processes and products. Weinheim: WILEY-VCH, 2008. p.165-200.

SANTOS, F. A.; COLODETTE, J.; QUEIROZ, J. H.. Bioenergia e Biorrefinaria: Cana-de-Açúcar e Espécies Florestais. Viçosa: UFV, 2013

SANTOS, F. A.; QUEIROZ, J. H.; COLODETTE, J. L.; FERNANDES, S. A.; GUIMARÃES, V. M.; REZENDE, S. T.. Potencial da palha de cana-de-açúcar para produção de etanol. Química nova, v.35, n.5, p.1004-1010, 2012. DOI: https://doi.org/10.1590/S0100-40422012000500025

SOBRINHO, O. P. L.; SILVA, L. F. B.; PEREIRA, A. I. S.; CANTANHEDE, E. K. P.; CARLOS, M. A. S.; SILVA, J. R.; SIQUEIRA, L. F. S.. Uma proposta de aula experimental utilizando mesocarpo de babaçu (Orbignyaspeciosa) na remoção do azul de metileno de soluções aquosas. Educación Quimica. v.26, n.4, p.314- 318, 2015. DOI: https://doi.org/10.1016/j.eq.2014.12.001

STREHLER, A.. Technologies of wood combustion. Ecological Engineering, v.16, p. 25-40, 2000. DOI: https://doi.org/10.1016/S0925-8574(00)00049-5

TOLMASQUIM, M. T.; GUERREIRO, A; GORINI, R.. Matriz energética brasileira: uma prospectiva. Novos Estud. CEBRAP, n.79, p.47-69, 2007. DOI: https://doi.org/10.1590/S0101-33002007000300003

WATKINGS, D.; NURUDDIN, M.; HOSUR, M.; TCHERBINARTEH, A.; JEELANI, S.. Extraction and characterization of lignin from different biomass resources. Journal of Materials Research and Technology, v.4, n.1, p.26-32, 2015. DOI: https://doi.org/10.1016/i.jmrt.2014.10.009

A CBPC - Companhia Brasileira de Produção Científica (CNPJ: 11.221.422/0001-03) detém os direitos materiais desta publicação. Os direitos referem-se à publicação do trabalho em qualquer parte do mundo, incluindo os direitos às renovações, expansões e disseminações da contribuição, bem como outros direitos subsidiários. Todos os trabalhos publicados eletronicamente poderão posteriormente ser publicados em coletâneas impressas sob coordenação da Sustenere Publishing, da Companhia Brasileira de Produção Científica e seus parceiros autorizados. Os (as) autores (as) preservam os direitos autorais, mas não têm permissão para a publicação da contribuição em outro meio, impresso ou digital, em português ou em tradução. 